\title{
UNA APROXIMACIÓN GEOGRÁFICO-JURÍDICA AL AGROTURISMO EN ESPAÑA DESDE EL PUNTO DE VISTA DE LA OFERTA
}

\author{
Martí Cors Iglesias* \\ Universitat de Barcelona \\ https://orcid.org/0000-0002-7625-6702
}

\section{RESUMEN}

La presente contribución pretende explorar la situación del agroturismo en España desde el punto de vista de la oferta. Tras un primer apartado teórico-conceptual sobre el agroturismo se analiza la presencia y tratamiento de dicha actividad en el marco jurídico-administrativo español y a continuación se aborda su distribución territorial. Pese a la existencia de un marco turístico favorable al agroturismo, acorde con las tendencias de la demanda turística actual y el elevado potencial turístico del territorio, el nivel de desarrollo e implantación del agroturismo en España es menor al de otros países europeos. La identificación del agroturismo y su individualización frente a otros tipos de turismo no está bien resuelta en España.

Palabras clave: agroturismo; turismo rural; marco normativo; sector agroalimentario; España.

\section{A Geographical and legal study of agritourism in Spain: A Supply-side perspective}

\section{ABSTRACT}

This paper seeks to explore the current state of agritourism in Spain by taking a supplyside perspective. Following on from a theoretical-conceptual analysis of agritourism, the presence of this activity within the Spanish legal-administrative framework and the provisions made for it therein are examined, and its territorial distribution within Spain is described. Despite the existence of a tourism framework that is apparently favourable to agritourism, given current trends in tourism demand and Spain's great potential for tourism, the level of development and implementation of agritourism in Spain is not as advanced as that in other European countries. The recognition of agritourism and, consequently, the development of

Fecha de recepción: 14 de febrero de 2019

Fecha de aceptación: 16 de julio de 2019

* Departamento de Geografia. Universitat de Barcelona. Carrer de Montalegre, 6-8. 08001 BARCELONA (España). E-mail: marti.cors@ub.edu 
an identity that is distinct from that of other types of tourism have not, as yet, been adequately addressed in Spain.

Keywords: agritourism; rural tourism; legal framework; agri-food sector; Spain.

\section{INTRODUCCIÓN}

El ocio y el turismo es un fenómeno prácticamente estructural en las sociedades postindustriales y contemporáneas del siglo XXI. El turista se ha convertido en un consumidor experimentado de su tiempo libre. El tiempo libre es ahora otro producto consumible al alcance de millones de personas en todo el mundo, desde las clases trabajadoras hasta las clases sociales más adineradas. La demanda de servicios es cada vez mayor y la industria turística es la encargada de proporcionarlos. Los nuevos productos turísticos se introducen con facilidad en el mercado y frente a la globalización la originalidad y singularidad del producto son variables que cotizan al alza. También hay un cambio cultural en la sociedad postmoderna y el turismo no puede disociarse de los cambios culturales (Urry, 1990). La perspectiva colectiva fue una fase de consumo masivo, donde el acceso al ocio fue una victoria de la clase media y se caracterizó por la uniformidad de los productos. Ahora estamos ante un deseo personal e individual del consumidor, donde se valora el ocio con referencia a la experiencia turística y con una perspectiva romántica y única del viaje que nos conduce hacia un producto de turismo a la carta. En el nuevo turismo a la carta las cuestiones de orden cultural y medioambiental adquieren suma importancia para el viajero y el espacio rural se convierte en lugar y soporte donde satisfacer sus necesidades. De esta manera, el consumidor desea contactar con la ruralidad y el campo, ya sea para encontrar sus propias raíces o simplemente para desconectar de la ciudad. Muchas generaciones de las sociedades urbanas actuales ya no mantienen sus lazos familiares con el entorno rural y, en consecuencia, se sienten atraídos por un espacio que les es ajeno. En definitiva, la demanda potencial y real que existe en relación a la oferta de turismo en los espacios rurales está más que acreditada. A todo ello cabe recordar que el amor e interés por el campo y la naturaleza emerge con fuerza a mediados y finales del siglo XX en el conjunto de países y sociedades postindustriales. Se trata de una tendencia o moda que se apoya en una imagen positiva y hasta cierto punto idealizada del espacio rural. El atractivo universal de las zonas rurales se encuentra en la vida cotidiana de la comunidad rural y en una apelación a la autenticidad del producto' ${ }^{1}$ (Cànoves et al., 2004). En este contexto, las políticas de protección y conservación del patrimonio natural y cultural desempeñan un

1 Existe un interesante debate acerca de la autenticidad y la calidad del producto turístico en el ámbito del turismo rural y el agroturismo. La autenticidad y la calidad son dos aspectos que deben ir en paralelo, pero en ocasiones la artificialidad de algunos productos en pro de una mayor calidad llega a ser contraproducente si los estándares de calidad ponen en riesgo su autenticidad. Por ejemplo, la ordenación y transformación de los interiores y exteriores de una granja para usos turísticos de acuerdo con los intereses de los huéspedes acaba dándole un cierto aire de artificialidad. 
papel muy importante en las dinámicas turísticas actuales ya que contribuyen a poner en valor los recursos del territorio (Shaw y Williams, 1994, Cors, Gómez y Armesto, 2018).

La presente aportación pretende aproximarse a la realidad jurídico-territorial del agroturismo en España. El trabajo parte de una revisión teórico-conceptual acerca del agroturismo para a continuación explorar su regulación e implantación en España. En primer lugar, se aborda la presencia y tratamiento del agroturismo en el marco jurídico de las diferentes Comunidades Autónomas -leyes y decretos que regulan el sector del turismo rural y el agroturismo- y, en segundo lugar, se analiza la distribución territorial de las explotaciones de agroturismo y sus singularidades en base a los datos oficiales del último censo agrario del año 2009.

\section{MARCO TEÓRICO-CONCEPTUAL}

El agroturismo ha sido debatido y tratado en numerosos artículos académicos (Roberts y Hall, 2001; Sayadi y Calatrava, 2001; Mamdy, Disez y Begon. 2001; Sharpley y Vass, 2006; Phillip, Hunter y Blackstock, 2010; Barbieri, Xu, Gil-Arroyo y Rich, 2015; Durrande-Moreau, Courvoisier y Bocquet, 2017). A menudo el agroturismo se ha interpretado como sinónimo de turismo rural pero el agroturismo no es sinónimo de turismo rural sino que es un subgrupo específico de turismo rural (Clarke, 1999). Organizaciones vinculadas al sector agrario y turístico han intentado definir aquellas cuestiones que están relacionadas con el agroturismo pero la divergencia de perspectivas entre agricultores y actores turísticos ha dificultado toda tentativa de proponer una definición sintética y completa de la acepción. La identificación del agroturismo con un tipo de turismo rural es la más común y aceptada (OCDE, 1994; Disez, 1996; Cors, 2004; Pulido, 2008) y está relacionada con las actividades turísticas ofertadas por los agricultores (Di Domenico y Miller, 2012; Tew y Barbieri, 2012). Sin embargo existen otras actividades relacionadas con el agroturismo que no han sido tratadas como tales al no ser identificadas con el turismo rural. Nos referimos, por ejemplo, a todas aquellas actividades del sector agroalimentario que suelen presentarse bajo otras terminologías o etiquetas -turismo gastronómico, oleoturismo, enoturismo, etc.-.

Desde el punto de vista etimológico el agroturismo significa toda relación que se pueda establecer entre el turismo y el medio agrario y da cabida a manifestaciones turísticas y de ocio de signo muy diverso. El enfoque dominante del agroturismo es aquel que lo relaciona con la existencia de una explotación agraria. Según Marcotte, Bourdeau y Doyon (2006), y a partir de un análisis comparado de 33 autores, la utilización de diferentes léxicos -agriturismo, agroturismo o turismo de granja- para identificar una misma actividad ha generado cierta confusión. Las terminologías utilizadas difieren de unos países a otros y lo que algunos denominan agroturismo otros, principalmente los anglosajones, lo llaman farm tourism. La distinción parece oportuna si por farm tourism se refiere al conjunto de visitantes que se alojan en una granja con un producto turístico profesionalizado y por agroturismo al conjunto de actividades de turismo y ocio relacionadas con el medio agrario, que incluye la anterior categoría más el resto de iniciativas turísticas con una clara vocación agraria -museos, ferias, mercados, venta directa de productos de la granja, etc.-. En este sentido, Durrande-Moreau et. al, (2017) abogan por una concepción amplia y transversal del agroturismo, por un agroturismo integrado que esté ligado al medio 
agrario y relacionado con sus productos, sus procedimientos, sus productores, sus espacios, sus valores y su cultura. Un agroturismo que pueda darse en lugares distintos y no únicamente en una granja y que pueda estar bajo la responsabilidad de otros actores, como asociaciones y cooperativas, y no solo a cargo de los agricultores. El tratamiento clásico del agroturismo excluye aquellas actividades que no están directamente relacionadas con la explotación agraria y el alojamiento rural, pero en los últimos años crece el número de autores que apuestan por un agroturismo inclusivo y diverso (Phillip et. al, 2010; Paül y Araújo, 2012; Arroyo, Barbieri y Rozier, 2013; Flanigan, Blackstock y Hunter, 2014; Durrande-Moreau et. al, 2017).

Ante una interpretación amplia del concepto, la identificación de diferentes tipos de agroturismo contribuye a mejorar su conocimiento y análisis. En el caso de Phillip, Hunter y Blackstock (2010) introducen una clasificación tipológica del agroturismo a partir de tres variables: a) la relación del producto turístico con la explotación agraria, b) la naturaleza del contacto entre la actividad turística y la actividad agraria y c) el grado de autenticidad en la experiencia turística. Según los mismos autores existen hasta cinco tipos diferentes de agroturismo: el agroturismo sin explotación agraria, el agroturismo en explotación agraria con contacto pasivo, el agroturismo en explotación agraria con contacto indirecto, el agroturismo en explotación agraria con contacto directo "agroturismo en escena" y, por último, el agroturismo en explotación agraria con contacto directo "agroturismo auténtico". En definitiva, el agroturismo se presenta bajo múltiples caras, desde una simple oferta de alojamiento turístico sin apenas contacto entre el huésped y el agricultor hasta un producto totalmente integrado en que la actividad turística y la actividad agraria están estrechamente interrelacionadas.

En relación al grado y nivel de desarrollo del agroturismo, según el geógrafo francés Roger Béteille (1996) inciden tres variables principales: primero, los sistemas de explotación agraria -estructura de la propiedad rústica, características y dimensión productiva y perfil de los titulares-; segundo, la intensidad de la demanda turística global en la región; y tercero, el volumen y la proximidad de la población urbana en términos de demanda potencial o captiva. En la mayoría de países desarrollados el agroturismo se afianza como oferta turística, pero todavía existen diferencias notables entre unos países y otros. En el caso de Europa, el contexto territorial y socioeconómico es favorable al desarrollo del agroturismo. Las causas principales de dicho desarrollo son: a) el factor proximidad de la demanda potencial; b) la estrecha relación existente entre los espacios rurales y urbanos; y c) las pautas de comportamiento recreativo de los ciudadanos europeos, que ponen en valor la ruralidad y la naturaleza. En la región alpina y en los espacios rurales cercanos a las principales conurbaciones de la Europa Occidental el agroturismo se encuentra en una fase de madurez y la oferta de productos es amplia y diversa -alojamiento en la granja, venta directa de productos, restauración, actividades pedagógicas y de ocio, etc.- . En cambio, en los países del sur y este de Europa el agroturismo se sitúa en una fase intermedia de desarrollo y su oferta está menos diversificada. Por otra parte, en muchas granjas del centro y norte de Europa el agroturismo ha pasado de ser una actividad complementaria a la agricultura a ser la actividad principal. Por ejemplo, según la Asociación National Farm Attraction Group de Inglaterra, en los años 1990 el 45\% de los ingresos de sus miembros provenían de la actividad turística y de ocio. En las explotaciones agrarias tirolesas y 
bávaras lo que en sus inicios fue una simple oferta de alojamiento ahora es una oferta profesionalizada de alojamiento y restauración. En definitiva, con el cambio de siglo el agroturismo ha experimentado dos procesos paralelos, por un lado, la diferenciación y separación física entre actividad agrícola y actividad turística y, por el otro, la profesionalización y especialización turística (Fleischer y Tchetchik, 2005). Una evolución y características del agroturismo que está relacionado con el nivel de desarrollo económico del país $\left(\right.$ Hegarty y Przezborska, 2004) ${ }^{2}$. Ante esta nueva realidad algunos planteamientos de base han tenido que reformularse: el agroturismo ya no debe ser tratado como una mera prolongación de la actividad agraria sino que hay que abordarlo como una actividad propia.

\section{EL AGROTURISMO EN ESPAÑA Y SU OFERTA. UNA APROXIMACIÓN JURÍDICA Y TERRITORIAL}

En el sur de Europa el agroturismo evoluciona en las últimas tres décadas desde estructuras simples de alojamiento hacia estructuras más profesionalizadas y diversificadas para captar a un cliente más exigente y heterogéneo. Aumenta el número de agricultores que ofrecen actividades relacionadas con las tareas agrícolas, la elaboración y venta de productos y otras actividades de ocio; y otros que optan por ampliar la oferta de alojamiento. A pesar de todo ello, no muchos años atrás y en zonas del Mediterráneo el turismo rural y el agroturismo todavía no había alcanzado su etapa de madurez y persistía el contraste entre regiones (Cànoves, et al., 2004). Por ejemplo, en algunas áreas rurales de la Europa meridional la oferta de agroturismo continuaba mostrando un bajo nivel de desarrollo -oferta escasa y poco diversificada-. Además, en el caso de España la visión parcial y poco individualizada del agroturismo no ha facilitado su desarrollo. Sayadi y Calatrava (2001) ya ponían de manifiesto el bajo nivel de desarrollo del agroturismo en comparación con otros países europeos, con una oferta muy poco significativa de apenas el 0,5\% de las explotaciones agrarias. Según ellos, las causas de esa baja tasa de actividad agroturística había que buscarlas en la existencia de una oferta poco definida y estructurada, la presencia de una demanda aún débil y reducida y, finalmente, en la propia definición normativa del agroturismo, ausente en algunos casos y dispar en otros.

A diferencia del agroturismo, el turismo rural ha experimentado un fuerte crecimiento en España a lo largo de las tres últimas décadas. Desde los años 1990 el boom de los alojamientos de turismo rural se traduce en un fuerte incremento de la oferta. De las 1.074 casas rurales abiertas en 1994 (Cànoves et. al, 2004) se ha pasado a las más de 17.600 en agosto de 2018 (Instituto Nacional de Estadística). El comportamiento de la demanda ha sido muy similar, con un incremento continuo del número de viajeros y de pernoctaciones salvo durante los años más duros de la crisis económica.

2 Un estudio comparado entre Polonia e Irlanda demuestra que en Polonia el agroturismo está gestionado por familias campesinas cuya actividad principal es la agricultura y el turismo está orientado a mantener las granjas y su estilo de vida en un contexto regional de rendas bajas. En cambio, en Irlanda los operadores turísticos orientan su producto turístico hacia modernos complejos de alojamiento situados en el medio rural. Mientras que en Polonia el atractivo turístico permanece vinculado a la autenticidad de la experiencia en una granja en Irlanda el turista no entra necesariamente en contacto con las tradiciones y costumbres del campo. 


\subsection{Aproximación jurídica}

En España las Comunidades Autónomas (CCAA) desempeñan un papel muy importante en el ámbito del turismo ya que asumen competencias legislativas en materia de promoción y ordenación turística. El agroturismo no es ajeno a dicha realidad y su despliegue y tratamiento se verá condicionado por el marco jurídico de cada Comunidad Autónoma. Sin restar ningún mérito a aquellas mujeres que fueron pioneras en el agroturismo, cuando a lo largo de los años 1970 abrieron las puertas de sus casas de labranza a los turistas, las bases del actual desarrollo y estructura del agroturismo se establecen en el nuevo Estado de las Autonomías. La reglamentación del turismo rural y el agroturismo arranca en los años 1980 en el País Vasco y en Cataluña. Ambas CCAA regulan el agroturismo por decreto y lo identifican con aquel servicio de alojamiento rural prestado por el agricultor e integrado en una explotación agraria. En una fase inicial de desarrollo los términos turismo rural y agroturismo se usan con frecuencia como sinónimos, pero con el paso de los años se impone la terminología turismo rural para referirse al conjunto de la oferta. A partir de los años 1990, y con la regulación del turismo rural en todas las Comunidades Autónomas, se dispara el número de denominaciones y tipologías de alojamientos, que difieren de unas comunidades a otras por falta de unos criterios comunes y que dificultan la unidad de mercado (Hernández, 2010). Frente al gran abanico de modalidades, de acuerdo con la normativa vigente en cada CCAA (Melgosa, 2005), el agroturismo pierde definitivamente peso y presencia a nivel jurídico.

A mediados de los años 2000 hay un cambio de rumbo en el marco normativo regulador del turismo en España debido a la entrada en vigor de la nueva directiva europea 2006/123/CE conocida también como Directiva Bolkestein. El objetivo de la Directiva es liberalizar el mercado turístico interno europeo, armonizar criterios y garantizar la libre circulación en la prestación de servicios. Las CCAA adaptan sus respectivas normativas a la nueva Directiva y en el caso del turismo rural se procede a la armonización de criterios en cuanto a denominaciones y categorías. En este sentido, resulta fundamental el fomento de la colaboración entre administraciones en relación a la regulación de los alojamientos rurales. Conscientes de que existe una disparidad total y absoluta de normativas que deja al consumidor totalmente desprotegido, en el marco de la Conferencia Sectorial de Turismo, celebrada en abril del 2013, se llega a un importante acuerdo entre Comunidades Autónomas que apuestan por una legislación más homogénea de los alojamientos rurales. Sin embargo, los cambios introducidos en el turismo rural de poco van a servir al agroturismo, que continuará carente de un trato más individualizado por parte de las administraciones públicas. En realidad la Directiva Bolkestaein lo que ha favorecido es la expansión de los alojamientos rurales de alquiler integrados en explotaciones agrarias, es decir, ha potenciado la vertiente inmobiliaria del agroturismo.

Del análisis de las distintas normativas a nivel autonómico que regulan el agroturismo en España se desprende, en primer lugar, una interpretación más bien restrictiva del propio concepto y asociado únicamente a un tipo de alojamiento y, en segundo lugar, un reconocimiento y trato desigual en función de la Comunidad Autónoma. A principios del año 2018 tan solo 8 de las 17 CCAA identificaban el agroturismo como una tipología o modalidad de turismo rural (véase tabla 1). El no reconocimiento explícita del agroturismo en los textos jurídicos de las restantes CCAA podía ser debido a varias causas: a) al bajo 
nivel de desarrollo e implantación del agroturismo en estos territorios; b) al significado del propio concepto, que va más allá de lo estrictamente regulable; y c) a la propia toma de decisiones por parte de los entes responsables, que deciden no diferenciar el agroturismo del resto de establecimientos de turismo rural ya que los criterios de clasificación de los alojamientos son otros -régimen de alojamiento, servicios prestados, ubicación y características de la casa rural, etc.-. Las CCAA en cuestión que no contemplan el agroturismo en sus respectivas normativas se sitúan preferentemente en el centro y levante peninsular -Castilla y León, Cantabria, La Rioja, Aragón, Madrid, Extremadura, Región de Murcia y Comunidad Valenciana-. En el caso de Extremadura, un territorio con un elevado potencial agroturístico (Campón et. al, 2010), se da la paradoja que el artículo 28 de su anterior ley de turismo -Ley 2/1997 de Turismo de Extremadura- identificaba y definía perfectamente el agroturismo, en cambio la ley actual de turismo lo suprime.

En relación a aquellas otras CCAA que sí establecen una regulación explícita para el agroturismo, tal y como ya se ha comentado con anterioridad, la mayoría de ellas lo identifican con una modalidad o tipo específico de alojamiento rural. No obstante, existen también ciertas diferencias entre unas comunidades y las otras. En algunas el agroturismo se asocia con una tipología o grupo específico de alojamiento rural -País Vasco, Islas Baleares y Castilla-La Mancha-, en otras se define como una modalidad transversal al conjunto de establecimientos de turismo rural -Principado de Asturias, Galicia y CataluñaPor último, la Comunidad Foral de Navarra segrega el agroturismo del resto del turismo rural y lo vincula con el sector agroalimentario.

Tabla 1

IDENTIFICACIÓN DEL AGROTURISMO EN EL MARCO NORMATIVO, 2018

\begin{tabular}{|c|c|c|c|}
\hline $\begin{array}{l}\text { Identificación del } \\
\text { agroturismo }\end{array}$ & CCAA & Ley / Decreto & Artículo \\
\hline \multirow{5}{*}{$\begin{array}{l}\text { El agroturismo como una tipolo- } \\
\text { gía básica de establecimiento de } \\
\text { turismo rural }\end{array}$} & \multirow{2}{*}{ País Vasco } & Decreto $199 / 2013$ & Artículo 3.1 \\
\hline & & Ley $13 / 2016$ & Artículo 49 \\
\hline & Islas Baleares & Decreto $20 / 2015$ & Artículo 103 \\
\hline & Castilla-La Mancha & Decreto $893 / 2006$ & Artículo 10 \\
\hline & Galicia & Decreto $191 / 2004$ & Artículo $2.1 \mathrm{c}$ ) \\
\hline $\begin{array}{l}\text { El agroturismo como un subgrupo } \\
\text { de casa rural }\end{array}$ & Andalucía & Decreto $20 / 2002$ & Anexo 1.1 \\
\hline \multirow{4}{*}{$\begin{array}{l}\text { El agroturismo como una moda- } \\
\text { lidad transversal al conjunto de } \\
\text { establecimientos de turismo rural }\end{array}$} & Galicia & Ley $7 / 2011$ & Artículo 68 \\
\hline & $\begin{array}{l}\text { Principado de Astu- } \\
\text { rias }\end{array}$ & Decreto $143 / 2002$ & Artículo 37.3 \\
\hline & $\begin{array}{l}\text { Comunidad Foral } \\
\text { de Navarra }\end{array}$ & \multicolumn{2}{|c|}{ Decreto $44 / 2014$} \\
\hline & Cataluña & Decreto $159 / 2012$ & Artículo 54 \\
\hline
\end{tabular}




\begin{tabular}{|c|l|c|c|}
\hline \multicolumn{1}{|c|}{$\begin{array}{c}\text { Identificación del } \\
\text { agroturismo }\end{array}$} & \multicolumn{1}{|c|}{ CCAA } & Ley / Decreto & Artículo \\
\hline $\begin{array}{l}\text { El agroturismo como una acti- } \\
\text { vidad propia y diferenciada del } \\
\text { turismo rural }\end{array}$ & $\begin{array}{l}\text { Comunidad Foral } \\
\text { de Navarra }\end{array}$ & \multicolumn{2}{|c|}{ Decreto 44/2014 } \\
\cline { 2 - 5 } & Islas Baleares & Ley 12/2014 & Arts. 85 a 90 \\
\hline
\end{tabular}

Fuente: Elaboración propia a partir de Diarios Oficiales de las Comunidades Autónomas.

\subsubsection{El agroturismo como un subtipo de turismo rural}

Durante las etapas iniciales del agroturismo la denominación casa de labranza identificaba a aquellos establecimientos de turismo rural gestionados por los agricultores e integrados en una explotación agraria. Tras el acuerdo entre administraciones para armonizar las diferentes tipologías de alojamientos rurales esta denominación fue substituida por la de casa rural. En el caso del País Vasco el agroturismo se utilizó como criterio básico para clasificar los alojamientos de turismo rural y fue una de las primeras Comunidades Autónomas en regularlo. En la actualidad se mantiene dicha regulación y su definición va en el mismo sentido que entonces (véase artículo 49 de la Ley 13/2016 de Turismo del País Vasco). En el País Vasco el agroturismo ha logrado individualizarse con cierto éxito del resto de alojamientos rurales.

"El agroturismo consiste en la prestación mediante precio de servicios turísticos de alojamiento con o sin restauración por parte de personas agricultoras y ganaderas en sus caseríos, integrados en una explotación agraria."

(Artículo 49 de la Ley 13/2016 de Turismo del País Vasco)

De igual modo, en otras CCAA -Galicia, Castilla-La Mancha y Andalucía- la normativa en turismo rural identifica al agroturismo con un grupo específico de alojamientos rurales. La diferencia con respeto al País Vasco es que en estas CCAA se contemplan otro tipo de variables a la hora de clasificar los establecimientos de turismo rural -ubicación física, régimen de alojamiento, características arquitectónicas e históricas del edificio, etc.-. La consideración de estas otras variables implica que el número total de tipologías sea mayor. En Galicia, por ejemplo, el decreto aún vigente clasifica los establecimientos de turismo rural en cuatro grupos y solo uno de ellos es de agroturismo. En el caso de Castilla-La Mancha el agroturismo también guarda una estrecha relación con las explotaciones de turismo cinegético, que el nuevo decreto sobre turismo rural ya prevé incorporar. Finalmente, en Andalucía se contempla el agroturismo como una de las once especialidades que pueden tener los alojamientos rurales (Melgosa, 2005).

De acuerdo con las últimas reformas legislativas aprobadas en materia de turismo rural, algunas CCAA definen el agroturismo como una modalidad transversal al conjunto de establecimientos de turismo rural con independencia de su tipología. El Principado de Asturias y Cataluña ya lo definieron de este modo en el año 2002 y Galicia lo hizo en 2011 (véase artículo 68 de la Ley 7/2011 de Turismo de Galicia). 
"Con independencia del grupo de alojamiento de turismo rural adoptado, la modalidad de agroturismo será de aplicación a los establecimientos que estuvieran integrados en explotaciones agrarias, ganaderas o forestales que, junto con el hospedaje, oferten servicios generados por la propia explotación, permitiendo la participación de las usuarias y usuarios turísticos en las tareas propias derivadas de las actividades agrarias, ganaderas o forestales."

(Artículo 68 de la Ley 7/2011 de Turismo de Galicia)

\subsubsection{El agroturismo vinculado al sector agrario y agroalimentario}

Aquel planteamiento más simple del agroturismo focalizado en el servicio de alojamiento se va superando paulatinamente ante el auge de nuevas ofertas relacionadas con la explotación y su producción agroalimentaria -visita de la explotación, degustación y venta de productos, etc.-. En los últimos años algunas CCAA ya han empezado a legislar en esa dirección. Es el caso de la Comunidad Foral de Navarra, que en 2014 aprobó una normativa específica para el agroturismo orientada a regular aquellas actividades turísticas relacionadas con empresas del sector agroalimentario (véase artículo 2 del Decreto foral 44/2014 de Agroturismo). Se trata pues de una visión diferente del agroturismo que va más allá del turismo rural y cuyo objetivo es fomentar el sector agroalimentario de Navarra, su conocimiento y el consumo de productos de proximidad.

"Se entiende por agroturismo la prestación, mediante precio, de actividades turísticas relacionadas con empresas agroalimentarias, tanto para el disfrute como para la formación del público y la promoción de los productos de dichas empresas." (Artículo 2 del Decreto foral 44/2014 de Agroturismo de la Comunidad Foral de Navarra)

Otro caso singular es el de las Islas Baleares, que con una dilatada trayectoria en materia de agroturismo y una fuerte implantación en la zona legisla las distintas actividades de agroturismo -alojamiento, ocio y cultura- desde el ámbito agrario (Ley 12/2014 agraria de las Islas Baleares). En esta ocasión, otro de los debates que atañe al agroturismo es desde que ámbito se debe legislar, si desde el ámbito turístico o por el contrario desde el ámbito agrario. Las actividades de agroturismo cabalgan sobre dos grandes ejes, el eje agrario y el eje turístico, y la problemática de fondo en cuanto a su definición y estructura pueda ser debida, en parte, a la falta de entendimiento y/o coordinación entre estos dos grandes sectores. En Baleares, por ejemplo, la fuerte presión turística que existe sobre el medio rural ha inducido a proteger las explotaciones agrarias del fenómeno turístico-residencial y, en consecuencia, la regulación del agroturismo se ha llevado a cabo desde la vertiente agraria. Pero en la mayoría de CCAA el agroturismo se ha abordado y regulado desde el ámbito turístico. Todo ello nos indica que desde las administraciones se deberían fortalecer los canales de colaboración entre ambos sectores -el agrario y turístico- con el propósito de afrontar mejor los retos y las necesidades del agroturismo. 


\subsection{Implantación territorial}

En España la falta de datos sobre el agroturismo dificulta su tratamiento y análisis geográfico. Normalmente la aproximación al agroturismo se lleva a cabo desde el turismo rural pero en esta ocasión se va hacer en base al censo agrario del año 2009. En aquel año en España había un total de 3.620 explotaciones de agroturismo, el 0,37\% de las explotaciones agrarias. De acuerdo con las cifras, la implantación territorial del agroturismo en España era aún muy débil, sobre todo si lo comparamos con otros países europeos. Solo en las Islas Baleares, Cataluña y el País Vasco el agroturismo superaba el 1\% de las explotaciones agrarias (véase tabla 2).

Tabla 2

DISTRIBUCIÓN DE LAS EXPLOTACIONES DE AGROTURISMO EN ESPAÑA POR COMUNIDADES AUTÓNOMAS, 2009

\begin{tabular}{|c|c|c|c|}
\hline \multirow[b]{2}{*}{ Comunidad Autónoma } & \multicolumn{3}{|c|}{ Explotaciones de agroturismo } \\
\hline & $\begin{array}{c}n^{0} \text { total de } \\
\text { explotaciones }\end{array}$ & $\begin{array}{l}\text { \% sobre el total } \\
\text { de explotaciones } \\
\text { agrarias }\end{array}$ & $\begin{array}{l}\% \text { sobre el total de } \\
\text { explotaciones } \\
\text { agrarias con actividades } \\
\text { complementarias }\end{array}$ \\
\hline Andalucía & 591 & 0,24 & 28,89 \\
\hline Aragón & 216 & 0,42 & 16,45 \\
\hline Asturias, Principado de & 187 & 0,82 & 41,93 \\
\hline Baleares, Islas & 264 & 2,48 & 54,10 \\
\hline Canarias & 121 & 0,90 & 17,72 \\
\hline Cantabria & 67 & 0,69 & 47,18 \\
\hline Castilla y León & 277 & 0,29 & 12,61 \\
\hline Castilla-La Mancha & 303 & 0,25 & 18,02 \\
\hline Cataluña & 679 & 1,14 & 29,29 \\
\hline Comunidad Valenciana & 151 & 0,13 & 19,04 \\
\hline Extremadura & 133 & 0,21 & 18,68 \\
\hline Galicia & 127 & 0,16 & 7,19 \\
\hline Madrid, Comunidad de & 42 & 0,53 & 20,00 \\
\hline Murcia, Región de & 80 & 0,25 & 27,87 \\
\hline $\begin{array}{l}\text { Navarra, Comunidad } \\
\text { Foral de }\end{array}$ & 123 & 0,80 & 24,45 \\
\hline Rioja, La & 18 & 0,18 & 7,83 \\
\hline País Vasco & 241 & 1,46 & 4,85 \\
\hline ESPAÑA & 3620 & $\mathbf{0 , 3 7}$ & 17,43 \\
\hline
\end{tabular}

Fuente: Elaboración propia a partir de los datos del Censo Agrario 2009. 
En líneas generales, el porcentaje de explotaciones agrarias con actividades complementarias relacionadas con la explotación era también muy bajo y con la excepción del País Vasco, que rondaba el 30\%, en las restantes CCAA se situaba por debajo del 5\%. Entre las explotaciones agrarias que llevaban a cabo otro tipo de actividades, el agroturismo estaba presente tan solo en un $17,4 \%$ de ellas. Un porcentaje que se elevaba hasta el $54,1 \%$ en las Islas Baleares y que superaba el $40 \%$ en otras provincias de la cornisa cantábrica y el arco mediterráneo (véase figura 1). En este sentido, se aprecia con claridad como en determinados territorios turísticos de costa -Baleares, Costa Brava, y Costa del Sol- y de montaña -Pirineos y cordillera Cantábrica- las explotaciones agrarias del traspaís aprovechan su renta de localización para diversificar sus actividades en base al turismo. Por el contrario, en amplias zonas del interior y oeste peninsular el porcentaje de explotaciones se situaba claramente por debajo del $20 \%$, y es que para muchos agricultores de la Meseta la actividad turística no figuraba entre sus prioridades a la hora de diversificar sus economías.

\section{Figura 1 \\ DISTRIBUCIÓN PROVINCIAL EN ESPAÑA DEL \% DE EXPLOTACIONES DE AGROTURISMO EN RELACIÓN AL CONJUNTO DE EXPLOTACIONES CON ACTIVIDADES COMPLEMENTARIAS, 2009}

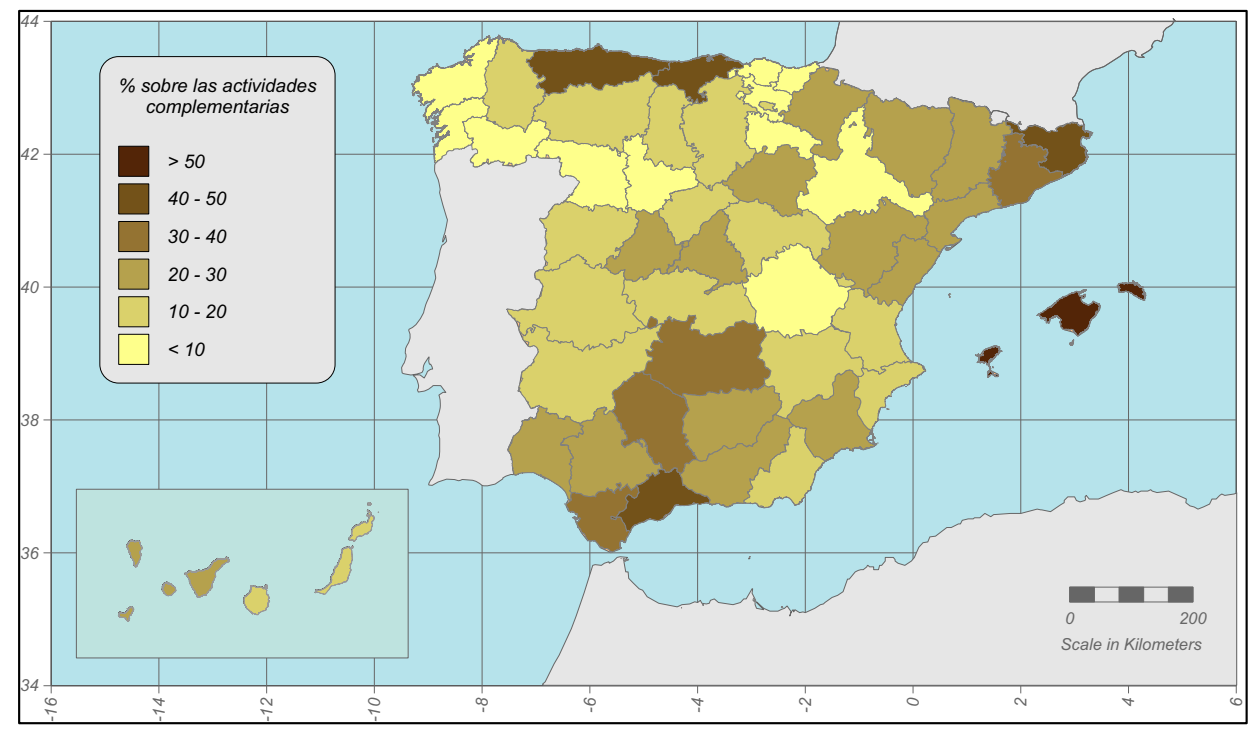

Fuente: Elaboración propia a partir de los datos del Censo Agrario de 2009.

Con el arranque del turismo rural a partir de los años 1980 la nueva oferta de agroturismo empieza a crecer por el extremo norte peninsular. La experiencia de otros países europeos como referente y el apoyo de las administraciones públicas -ayudas al turismo 
rural- contribuirán a su desarrollo. En el País Vasco el agroturismo en establecimientos de turismo rural empieza en el año 1988, cuando el ejecutivo autonómico y las tres diputaciones forales elaboraron un programa que daba opción a los propietarios de viviendas rurales de ofertar alojamiento a particulares, apoyado por un programa de ayudas económicas que podían alcanzar hasta el $40 \%$ de las obras. A partir de entonces se inició una labor de promoción y divulgación para dar a conocer el agroturismo en esta región (Campón et. al, 2008). En Cataluña la estrategia fue muy similar y el decreto sobre Residencies-Cases de Pagès del año 1983 marcó el inicio del agroturismo en casas de labranza (Cors, 2004). A lo largo de la década siguiente el agroturismo se extendió por el resto de Comunidades Autónomas pero la oferta continuaba siendo sensiblemente mayor en provincias del norte peninsular y en Baleares. En el año 2009 tan solo once provincias españolas superaban el centenar de explotaciones de agroturismo -Islas Baleares, Girona, Barcelona, Tarragona, Lleida, Huesca, Navarra, Guipúzcoa, Asturias, Ciudad Real y Málaga- (véase figura 2).

De acuerdo con la distribución geográfica de la oferta hay espacios rurales que son más afines o favorables al desarrollo del agroturismo. En primer lugar, tendríamos algunos espacios rurales altamente turistificados situados en el traspaís litoral o bien en la alta montaña -Baleares, Málaga, Girona y los Pirineos-. Se trata de unos espacios afectados por fuertes procesos de turistificación y en que el agroturismo vinculado al alojamiento rural aprovecha su renta de localización para desarrollarse. Al igual que ocurre con el resto del turismo rural, en estas zonas el agroturismo está muy relacionado con la estrategia de rentabilizar el patrimonio inmobiliario rural a través del alquiler turístico. En segundo lugar, están aquellos espacios rurales de la España húmeda con un poblamiento rural disperso y no excesivamente lejos de los núcleos urbanos -País Vasco y Principado de Asturias-. En estas zonas el agroturismo goza de un marco óptimo de desarrollo ya que las pequeñas explotaciones agrarias tienen que optar por la estrategia de la diversificación si quieren sobrevivir y las actividades de agroturismo encajan bien con la orientación y dimensión productiva de las mismas. Un claro ejemplo serían los caseríos vascos. En estos casos las dos actividades -la turística y la agraria- pueden presentar un mayor nivel de interrelación. En tercer lugar, existe un amplio espacio rural situado en el suroeste peninsular y caracterizado por la existencia de una estructura agraria latifundista -Ciudad Real, zonas de Extremadura y de Andalucía-. En algunas provincias de la España meridional las explotaciones de agroturismo experimentan un repunte y muchas de ellas están relacionadas también con el turismo cinegético -práctica de la caza-. En el resto de España, y muy especialmente en zonas de Castilla y Galicia, la presencia del agroturismo es menor y en algunas provincias -Guadalajara, Zamora y Ourense- es casi testimonial. 


\section{Figura 2 \\ DISTRIBUCIÓN PROVINCIAL EN ESPAÑA DEL N DE EXPLOTACIONES DE AGROTURISMO, 2009}

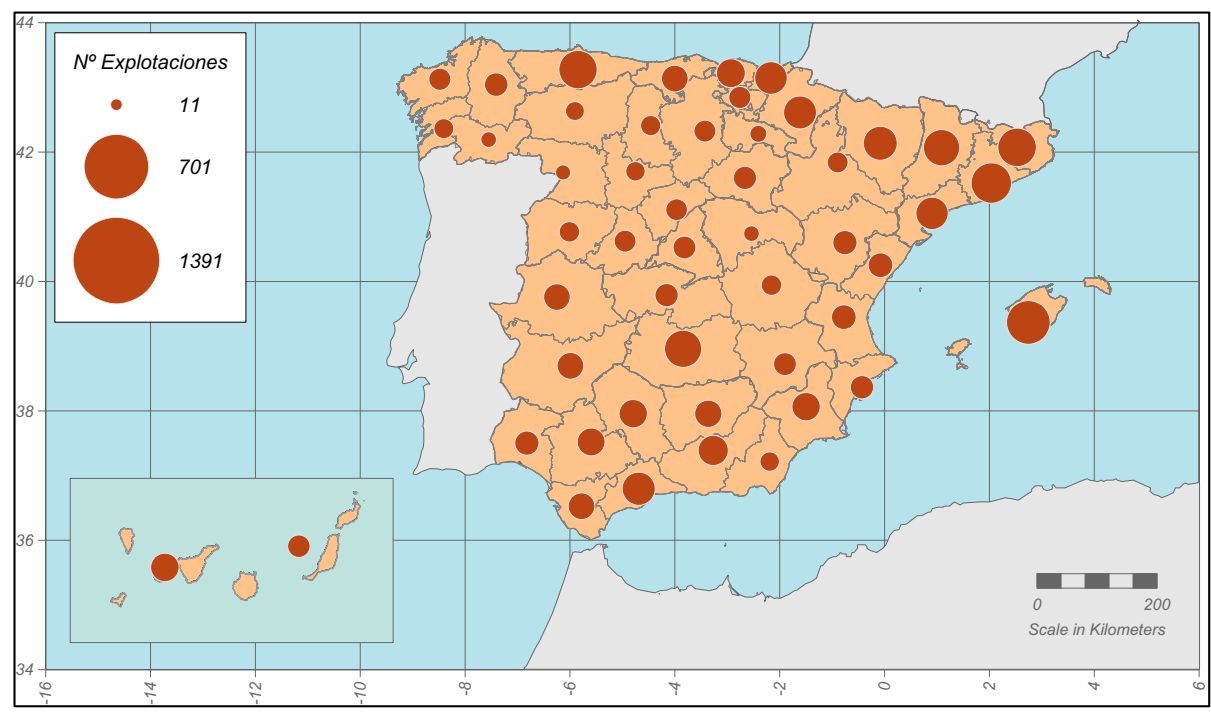

Fuente: Elaboración propia a partir de los datos del Censo Agrario de 2009.

Si comparamos el número de explotaciones de agroturismo con la oferta de alojamientos de turismo rural (véase figura 3) se observa con claridad que en 2009 la oferta de turismo rural era claramente superior a la de agroturismo. Aunque gran parte de la oferta de agroturismo esté formada por los propios alojamientos rurales, el análisis comparativo nos indica que el agroturismo era minoritario dentro del sector de los alojamientos de turismo rural, muy especialmente en zonas como Castila y León o la Comunidad Valenciana. Incluso en Cataluña, con una oferta mayor de explotaciones agroturísticas, tan solo una tercera parte de los alojamientos rurales eran de agroturismo. En definitiva, en la mayoría de provincias españolas el boom de los alojamientos de turismo rural no fue secundado por el agroturismo y únicamente en zonas muy puntuales como Guipúzcoa, Baleares o Ciudad Real la oferta de agroturismos era parecida o algo superior a la de los alojamientos de turismo rural. 


\section{Figura 3 \\ DISTRIBUCIÓN PROVINCIAL EN ESPAÑA DEL N DE ALOJAMIENTOS DE TURISMO RURAL ABIERTOS EN AGOSTO DE 2009}

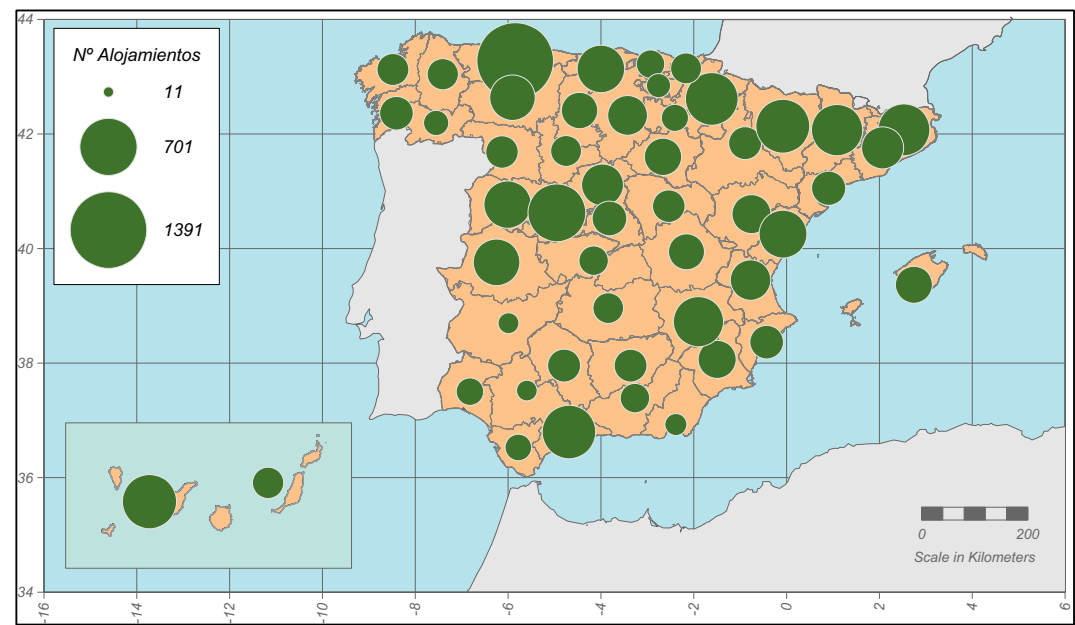

Fuente: Elaboración propia a partir de los datos del Instituto Nacional de Estadística (INE).

\subsubsection{El sector agroalimentario, una ventana de oportunidad para el agroturismo}

La gastronomía, la elaboración, promoción y venta de productos agroalimentarios es el otro gran pilar del agroturismo, con un fuerte potencial de proyección y desarrollo en España. La promoción de la industria agroalimentaria mediante la transformación de productos en la explotación agraria es una de las medidas de desarrollo rural que fomentan las administraciones públicas con el objetivo de afianzar la diversificación económica de las explotaciones y promover los productos alimentarios locales y de calidad. En ocasiones, los procesos de transformación de productos agroalimentarios en la explotación acaban vehiculándose como oferta turística. Legislar sobre la venta directa de productos agroalimentarios denota el interés que existe en potenciar este tipo de actividades -vender el producto agrario a un precio más justo para el agricultor- y a la vez regular una práctica que de manera informal había sido muy habitual en el medio rural español. Pese a ello, en la mayoría de CCAA la normativa que regula el agroturismo no contempla este tipo de actividades a no ser que estén vinculadas a la existencia de un alojamiento rural. La concepción del agroturismo asociado a un subtipo de alojamiento rural está todavía muy arraigada en España lo que dificulta la creación de estructuras colaborativas más amplias, similares a las que ya existen en otros países europeos ${ }^{3}$, y en las que puedan participar también aquellas otras explotaciones de agroturismo no vinculadas al turismo rural.

3 En Francia, las asociaciones de agroturismo Bienvenue à la ferme y Accueil Paysan aglutinan las explotaciones agrarias que ofertan servicios de alojamiento turístico, restauración, venta de productos, y otras actividades pedagógicas y de ocio. 
Según el último censo agrario, el número de explotaciones agrarias que transformaban productos agrícolas en España era especialmente significativo en Galicia, el País Vasco y Canarias, sobre todo en las provincias de Guipúzcoa, Álava, Pontevedra y Ourense (véase figura 4). En el resto de la Península y en Baleares los valores eran más discretos. Sin conocer con exactitud, por falta de información, si las explotaciones agrarias que transformaban productos agrarios lo vehiculaban o no como oferta turística, la mayor o menor presencia de este tipo de actividades en el territorio sí que nos permite identificar con mayor claridad hacia donde podría orientarse el agroturismo. En el caso de Galicia, por ejemplo, la fortaleza del agroturismo podría recaer en las actividades de transformación de productos agrícolas, y su posible venta directa, y en la oferta de actividades pesqueras. Para las zonas productoras de vino y aceite el eje de desarrollo del agroturismo giraría en torno a esos productos -oferta de enoturismo y oleoturismo-. En este sentido, la Rioja, la Mancha, la Ribera del Duero, Tarragona o Jaén serían territorios con fuerte potencial agroturístico.

\section{Figura 4 \\ DISTRIBUCIÓN PROVINCIAL EN ESPAÑA DEL No DE EXPLOTACIONES CON ACTIVIDADES COMPLEMENTARIAS DE TRANSFORMACIÓN DE PRODUCTOS AGRÍCOLAS, 2009}

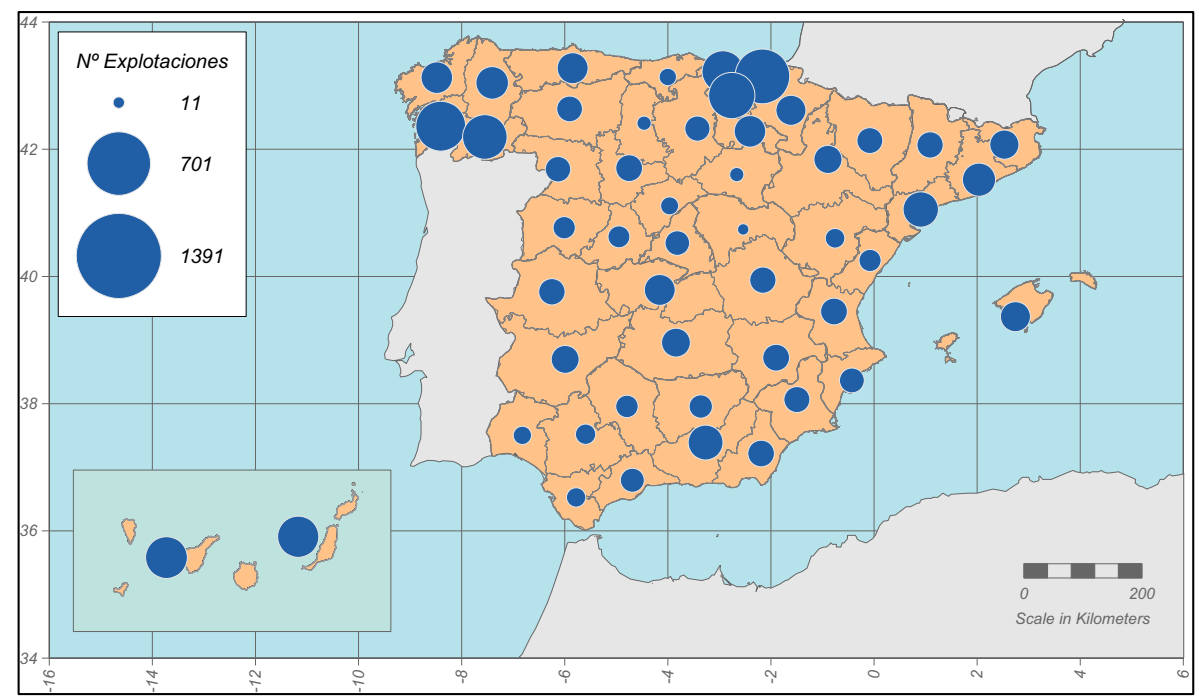

Fuente: Elaboración propia a partir de los datos del Censo Agrario de 2009.

En el caso del País Vasco, donde las actividades de agroturismo presentan un alto nivel de desarrollo y diversificación, especialmente en la provincia de Guipúzcoa, en el año 2017 el $40 \%$ de los alojamientos de turismo rural y agroturismo asociados a Nekatur practicaban la venta directa de productos (véase tabla 3). Entre los productos más ofertados figuraban la sidra, el queso, los huevos y el txakolí. (Véase figura 5). En Guipúzcoa, por ejemplo, la elaboración y venta de sidra se ha convertido en el producto estrella de los caseríos y las sidrerías son un auténtico fenómeno social que contribuye al desarrollo local de la zona -comarca de Donostialdea-. 
Tabla 3

OFERTA DE ALOJAMIENTOS DE AGROTURISMO Y DE TURISMO RURAL EN EL PAÍS VASCO Y OTRAS ACTIVIDADES ASOCIADAS, 2017

\begin{tabular}{|c|c|c|c|c|c|c|c|}
\hline \multirow[b]{2}{*}{ Provincias } & \multirow[b]{2}{*}{$\begin{array}{l}\text { Número de } \\
\text { alojamientos }\end{array}$} & \multicolumn{6}{|c|}{ Porcentaje (\%) } \\
\hline & & $\begin{array}{c}\text { Casa de } \\
\text { Agroturismo }\end{array}$ & $\begin{array}{l}\text { Casa } \\
\text { Rural }\end{array}$ & $\begin{array}{c}\text { Actividad } \\
\text { agraria }\end{array}$ & $\begin{array}{l}\text { Actividad } \\
\text { ganadera }\end{array}$ & $\begin{array}{c}\text { Elaboración } \\
\text { productos }\end{array}$ & $\begin{array}{c}\text { Venta de } \\
\text { productos }\end{array}$ \\
\hline Guipúzcoa & 132 & 69,7 & 30,3 & 61,4 & 48,5 & 16,7 & 38,6 \\
\hline Vizcaya & 72 & 37,5 & 62,5 & 51,4 & 40,3 & 4,2 & 38,9 \\
\hline Álava & 47 & 51,1 & 48,9 & 63,8 & 25,5 & 12,8 & 46,8 \\
\hline PAÍS VASCO & 251 & 57 & 43 & $\mathbf{5 9 , 0}$ & 41,8 & 12,4 & 40,2 \\
\hline
\end{tabular}

Fuente: Elaboración propia a partir de la asociación Nekatur.

Figura 5

VENTA DE PRODUCTOS EN ALOJAMIENTOS DE AGROTURISMO Y TURISMO RURAL DEL PAÍS VASCO, 2017

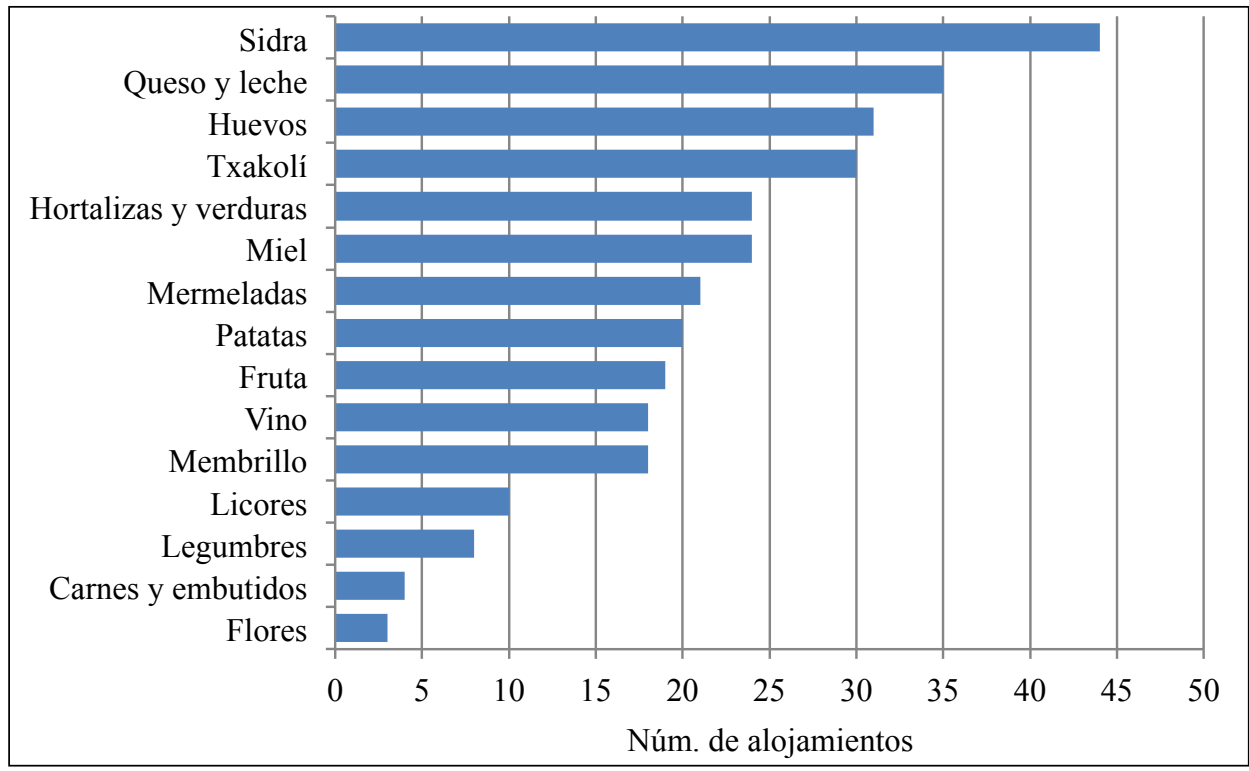

Fuente: Elaboración propia a partir de la asociación Nekatur.

En Cataluña, y con la finalidad de impulsar actividades de ocio y turismo en explotaciones agrarias, se puso en marcha en 2016 el programa Benvinguts a Pagès. La iniciativa consiste en ofertar una serie de propuestas -visita a las explotaciones agrarias, degustación y venta de productos locales, pernoctación en alojamientos de turismo rural, restauración, 
rutas temáticas y otras actividades complementarias- en el medio rural y durante todo un fin de semana. El principal objetivo es que los visitantes -público familiar y de origen urbano- conozcan las actividades y productos de las explotaciones agrícolas y ganaderas y, de este modo, potenciar la venta directa. Las explotaciones participantes deben estar acreditadas para la venta de proximidad de productos agroalimentarios -decreto 24/2013-. El evento también interpela al sector de la restauración, del turismo rural y a otras actividades complementarias de ocio. En la edición del año 2018, celebrada durante el mes de junio, participaron cerca de 240 explotaciones agrarias y el número total de participantes fue de unos 800 (véase tabla 4). Por provincias, Barcelona y Lleida fueron las que contaron con un mayor número de participantes, 237 y 235 respectivamente. La provincia de Barcelona fue además la que contó con un mayor nivel de participación de las explotaciones agrarias, detectándose un agroturismo vinculado al ocio y a la no pernoctación.

En relación a la tipología de productos ofertados por las explotaciones agrarias que participaron en la edición del año 2018 (véase tabla 5) cabe destacar, en primer lugar, la elevada presencia de productores ecológicos -un $46 \%$ de las explotaciones-. La producción ecológica es un rasgo en común que tenían casi la mitad de las explotaciones. Otro de los aspectos a resaltar es que en aquellos territorios que disponían de marcas o distintivos de calidad en relación al producto (DO, DOP o IGP) no se detectó una participación más elevada que en el resto. Solo se produjo un repunte de la participación en aquellas regiones vitícolas con denominación de origen. Con relación al tipo de producto ofertado, este guarda una estrecha relación con el territorio y su paisaje agrario. En este sentido, en la mitad sud de Cataluña, y muy especialmente en la provincia de Tarragona en la que hay un predominio casi absoluto de los cultivos leñosos, los productos más ofertados fueron el vino, el aceite, la fruta fresca y la fruta seca. Mientras que en las comarcas de montaña de la mitad norte de Cataluña, al ser espacios eminentemente ganaderos, predominaron las carnes, los embutidos y los quesos. Finalmente, las verduras y hortalizas, unos productos también asociados a los paisajes de huerta de las cercanías de Barcelona, estuvieron presentes en muchas de las explotaciones agrarias. En definitiva, vinos, aceites, verduras y hortalizas fueron la clase de productos más ofertados en el evento agroturístico.

Tabla 4

\section{PARTICIPANTES EN LA TERCERA EDICIÓN DE BENVINGUTS A PAGÈS 2018 (CATALUÑA)}

\begin{tabular}{|l|c|c|c|c|c|c|}
\hline Provincias & $\begin{array}{c}\text { Explotaciones } \\
\text { agrarias }\end{array}$ & Restaurantes & Alojamientos & $\begin{array}{c}\text { Actividades } \\
\text { complementarias }\end{array}$ & Rutas & Total \\
\hline Barcelona & 93 & 58 & 52 & 34 & 0 & 237 \\
\hline Girona & 41 & 34 & 60 & 20 & 0 & 155 \\
\hline Lleida & 57 & 46 & 92 & 35 & 5 & 235 \\
\hline Tarragona & 46 & 36 & 67 & 26 & 2 & 177 \\
\hline CATALUÑA & $\mathbf{2 3 7}$ & $\mathbf{1 7 4}$ & $\mathbf{2 7 1}$ & $\mathbf{1 1 5}$ & $\mathbf{7}$ & $\mathbf{8 0 4}$ \\
\hline
\end{tabular}

Fuente: Elaboración propia a partir de la página web Benvinguts a Pagès. 
Tabla 5

PERFIL DE LOS PRODUCTOS AGROALIMENTARIOS OFERTADOS EN LA TERCERA EDICIÓN DE BENVINGUTS A PAGÈS 2018 (CATALUÑA)

\begin{tabular}{|l|c|c|}
\hline \multirow{2}{*}{ Tipología de productos } & \multicolumn{2}{|c|}{ Explotaciones agrarias } \\
\hline Productos con etiqueta & $\mathbf{n}^{\mathbf{0}}$ & $\mathbf{\%}$ \\
\hline Productor ecológico & 109 & 46,0 \\
\hline Producción integrada (CCPI) & 5 & 2,1 \\
\hline Denominación de Origen (DO) & 39 & 16,5 \\
\hline Denominación de Origen Cataluña & 7 & 3,0 \\
\hline Denominación de Origen Protegida (DOP) & 12 & 5,1 \\
\hline Indicación Geográfica Protegida (IGP) & 5 & 2,1 \\
\hline Tipos de productos & $\mathbf{n}^{\mathbf{o}}$ & $\mathbf{\%}$ \\
\hline Arroz y otros cereales & 6 & 2,5 \\
\hline Aves de corral y huevos & 19 & 8,0 \\
\hline Bebidas (vinos, cavas y otras) & 51 & 21,5 \\
\hline Carne y embutidos & 47 & 19,8 \\
\hline Quesos y lácticos & 41 & 17,3 \\
\hline Fruta fresca & 38 & 16,0 \\
\hline Frutos secos & 15 & 6,3 \\
\hline Hierbas aromática, miel y otros dulces & 32 & 13,5 \\
\hline Legumbres & 10 & 4,2 \\
\hline Aceite y olivas & 54 & 22,8 \\
\hline Pescado y marisco & 4 & 1,7 \\
\hline Verduras, hortalizas y setas & 48 & 20,3 \\
\hline
\end{tabular}

Fuente: Elaboración propia a partir de la página web Benvinguts a Pagès. 


\section{CONCLUSIÓN}

Durante las etapas iniciales del agroturismo y el turismo rural en España -años 1980 y 1990- los argumentos esgrimidos para su impulso y desarrollo fueron la diversificación de las economías agrarias y la ocupación de la mano de obra familiar, principalmente femenina, con el objetivo de mantener las estructuras socio-productivas de las explotaciones y evitar así su abandono. En esta primera fase de implantación, gran parte de las iniciativas en agroturismo se insertaron dentro de la lógica de complemento de rentas. Con el cambio de siglo la oferta de alojamientos rurales experimentó un fuerte incremento y el agroturismo se mantuvo en una tendencia más o menos estable. Los nuevos actores en turismo rural y agroturismo pasaron a actuar cada vez más en clave patrimonial y empresarial -inversión y rentabilización de un bien inmueble- aunque no desaparecieron aquellos quienes continuaron apostando por un agroturismo más tradicional. En las etapas más recientes del turismo rural y el agroturismo, ambos sectores han experimentado un proceso de profesionalización y han tomado conciencia de que deben prestar unos servicios de mayor calidad. Mientras tanto, el marco normativo regulador de la oferta continúa mostrando la complejidad del fenómeno agroturístico en cuanto a su reconocimiento e identificación.

El potencial agroturístico de España es elevado, tanto por las propias características geográficas del territorio -presencia de agricultores, actividades agropecuarias y predominio de amplios espacios rurales en todo país- como por la existencia de una demanda potencial o captiva interesada en el consumo de productos de agroturismo -pernoctar en una granja, degustar y adquirir productos de la explotación, contemplar y/o participar en tareas agrícolas, asistir a actividades de tipo pedagógico, etc.-. No obstante, el estudio nos arroja unos resultados todavía modestos en cuanto a su nivel de desarrollo. Las posibles causas podrían ser, entre otras:

- La relativa juventud del fenómeno del agroturismo en comparación con otros países europeos. A pesar de que en algunas zonas de España el turismo rural pudiera estar entrando en una fase de madurez, en el caso específico del agroturismo es todavía prematuro diagnosticar su situación debido a la falta de información.

- La escasa implicación de los agricultores con la actividad turística, que puede ser atribuida a varios factores: 1) la propia naturaleza y dinámica de la actividad turística que es difícil a veces compaginarla con la actividad agraria, 2) los elevados costes económicos que conlleva la transformación de antiguos edificios rurales en modernos y confortables alojamientos turísticos, 3) una actitud conservadora del agricultor frente el cambio y 4) un entorno rural y agrario poco favorable al desarrollo del agroturismo debido a las bajas tasas de desarrollo turístico general de la zona, a la falta de servicios básicos, al escaso dinamismo emprendedor o al predominio de las explotaciones agrarias de tipo productivista.

- El actual marco legislativo del agroturismo, ausente en algunas Comunidades Autónomas, dispar en otras y, en líneas generales, bastante restrictivo en cuanto a diversidad de ofertas posibles. El auge de nuevas actividades relacionadas con los productos alimentarios y el ocio debería hacer replantear y/o flexibilizar la normativa. 
Para concluir, entre los retos que debería afrontar el agroturismo en España estarían, en primer lugar, los de orden conceptual. Hace falta una interpretación más integral de la actividad, poniendo el foco de atención no tan solo en los servicios de alojamiento turístico sino también en el conjunto de actividades relacionadas con la explotación agraria, sus tareas, sus productos y su cultura. Todo ello contribuiría a fortalecer la musculatura del propio concepto y sería más fácil individualizarlo del resto del turismo rural. A menudo los Estados han elaborado una doctrina de desarrollo del agroturismo mal individualizada y bajo el paraguas del turismo rural que ha marcado su desarrollo. En segundo lugar, ahondar en la idea de que el marco conceptual del agroturismo debe abrirse hacia nuevas realidades que están en pleno auge en nuestro país como puedan ser, por ejemplo, todas aquellas iniciativas turísticas relacionadas con la gastronomía, la producción agroalimentaria y la venta y consumo de productos autóctonos y de proximidad. El turismo vivencial y personalizado con un baño de autenticidad -tematización de la vida rural, degustación y compra de productos de la explotación, etc.- representa una gran oportunidad para aquellas pequeñas y medianas explotaciones agrarias que deseen subsistir frente al modelo productivista y globalizado del mercado actual. La creación de un producto agroturístico diversificado y profesionalizado sería más viable si las explotaciones integrasen su oferta de alojamiento con el resto de actividades de la finca. Finalmente, y, en tercer lugar, otro de los retos a superar es la falta generalizada de estructuras colaborativas en forma de asociaciones y/o plataformas digitales especializadas en agroturismo. Los alojamientos agroturísticos en España siguen estando presentes en asociaciones y plataformas de turismo rural, pero en otros países europeos existen redes y estructuras colaborativas específicas para el agroturismo-Tiroler Bauern, Irish Farm Hollydays, Bienvenue à la Ferme, Accueil Paysan-. La falta de acuerdo entre Comunidades Autónomas a la hora de definir y regular el agroturismo en base a unos criterios comunes dificulta toda tentativa de crear redes similares a nivel estatal. $\mathrm{Su}$ existencia permitiría racionalizar las actuaciones del sector $\mathrm{y}$, en definitiva, defender con mayor eficiencia y eficacia los intereses del agroturismo.

Como reflexión final apuntar que la llamada España vaciada podría ser un escenario de futuro para el agroturismo. En la más que posible y deseable incorporación de nuevos agricultores en esos territorios vacíos, en su etapa inicial es básico y fundamental poder alternar la actividad agraria con otro tipo de actividades ya que la puesta en funcionamiento de cualquier explotación agraria es siempre difícil y costosa al comienzo, más los réditos a medio y largo plazo. El agroturismo sería un buen complemento y/u oportunidad para la nueva actividad, de más fácil arranque e ingresos inmediatos. En definitiva, para que este escenario fuera real harían falta también un buen paquete de medidas públicas encaminadas a incentivar y ayudar a los nuevos agricultores $\mathrm{y}$, en general, a mejorar los servicios en el medio rural. Al fin y al cabo no debemos olvidar que son los agricultores, ganaderos, silvicultores y pescadores no solo quienes nos proveen de alimentos y otras materias primas sino también quienes nos mantienen el territorio y sus paisajes, unos paisajes que a la vez son contemplados y disfrutados por todos nosotros. 


\section{AGRADECIMIENTOS}

Esta contribución ha sido realizada en el marco del proyecto de investigación del Programa Estatal de Investigación, Desarrollo e Innovación orientada a los retos de la Sociedad del Ministerio de Economía, Industria y Competitividad del Gobierno de España, con referencia CSO2017-88935-R y del Grup de Recerca Consolidat Territori, Turisme i Canvi Climàtic de la Generalitat de Catalunya.

\section{BIBLIOGRAFÍA}

ARROYO, A., BARBIERI, C. y ROZIER RICH, S. (2013): "Defining agritourism. A comparative study of Stakeholders. Perceptions in Missouri and North Carolina", Tourism Management, vol. 37, pp. 39-47.

BÉTEILLE, R. (1996) : "L'agritourisme dans les espaces ruraux européens“, Annales de Géographie, $\mathrm{n}^{\circ}$ 592, pp. 584-602.

BARBIERI, C., XU, X., GIL-ARROYO, C. y RICH, S. R. (2015) : “Agritourism, Farm Visit, or... ? A Branding Assessment for Recreation Farms", Journal of Travel Research vol. 55 (8), pp. 1.094-1.108.

BRUNET, I. y ALARCÓN, A. (2008): "El turismo rural en Cataluña. Estrategias empresariales". Revista Internacional de Sociología, vol. 66 (49), pp. 141-165.

BURTON, R. (2004): "Seeing Through the 'Good Farmer's' Eyes: Towards Developing an Understanding of the Social Symbolic Value of "Productivist" Behaviour", Sociologia Ruralis. Journal of the European Society for Rural Sociology, vol. 44 (2), pp. 195-215.

CÀNOVES, G., VILLARINO, M., PRIESTLEY, G.K. y BLANCO, A. (2004): "Rural tourism in Spain: An analysis of recent evolution", Geoforum, vol, 35 (6), pp. 755-769.

CÀNOVES, G., GARAY, LL. y DURO, J.A. (2012): “Turismo rural en España: Avances y retrocesos en los últimos veinte años", Papers de Turisme, $\mathbf{n}^{\circ}$ 51, pp. 7-21.

CAMPÓN, A.M., LECO, F., PÉREZ, A. y HERNÁNDEZ, J.M. (2010): “Agroturismo en Extremadura: una oportunidad para la diversificación económica de las áreas rurales", en Territorio, paisaje y patrimonio rural: Actas del XV Congreso de Geografía Rural, Cáceres, Universidad de Extremadura-AGE, pp. 466-476.

CLARKE, J. (1999): "Marketing Structures for Farm Tourism: Beyond the Individual Provider of Rural Tourism", Journal of Sustainable Tourism, vol. 7 (1), pp. 26-47.

CORS, M. (2004): Agroturisme i territori a Catalunya. Anàlisi a diferents escales espacials (Tesis doctoral), Universitat de Barcelona.

CORS, M., GÓMEZ, M.B. y ARMESTO, X. (2018): "La apuesta por el patrimonio histórico-artístico en el turismo de montaña. El caso del Pirineo catalán", Scripta Nova, vol. XXII, 588, pp. 1-38.

DI DOMENICO, M.L. y MILLER, G. (2012): "Farming and tourism enterprise: experiential authenticity in the diversification of independent small-scale family farming", Tourism Management, vol. 33 (2), pp. 285-294.

DISEZ, N. (1996) : Agritourisme et développement territorial. Exemples dans le Massif Central (Tesis doctoral), Université Blaise Pascal de Clermont-Ferrand II. “..” 
DURRANDE-MOREAU, A., COURVOISIER, F.H. y BOCQUET, A.M. (2017): "Le nouvel agritourisme intégré, une tendance du tourisme durable", Téoros. Revue de Recherche en Tourisme, vol. 36 (1), pp. 62-74.

FLANIGAN, S., BLACKSTOCK, K. y HUNTER, C. (2014): "Agritourism from the perspective of providers and visitors: A typology-based study", Tourism Management, vol. 40, pp. 394-405.

HERNANDEZ MAESTRO, R.M. (2010) : "La normativa española sobre el turismo rural”, Estudios Turísticos, $\mathrm{n}^{\circ} 183$, pp. 25-41.

KAYSER, B. (1996): Ils ont choisi la champagne. Saint-Etienne, Éditions de l'Aube.

MAMDY, J.F., DISEZ, N. y BEGON, M. (2001): "Agritourisme et territoire. Le cas du Massif central”, Téoros. Revue de Recherche en Tourisme, vol. 20 (2), pp. 44-51.

MARCOTTE, P., BOURDEAU, L. y DOYON, M. (2006): "Agrotourisme, agritourisme et tourisme à la ferme? une analyse comparative", Téoros. Revue de Recherche en Tourisme, vol. 25 (3), pp. 59-67.

MELGOSA, F.J. (2005): "El régimen jurídico-administrativo de los alojamientos rurales en España", en Aurioles, J. (Coord.) IV, V, VI Jornadas de Derecho Turístico en Andalucía, Sevilla, Consejería de Turismo y Deportes de Junta de Andalucía, pp. 87-138.

OCDE (2004): Rural Tourism in Europe: Experiences, Development and Perspectives. Madrid, Organización Mundial del Turismo.

PAÜL, V. y ARAÚJO, N. (2012): “Agroturismo en entornos periurbanos: enseñanzas de la iniciativa holeriturismo en el Parc Agrari del Baix Llobregat (Cataluña)", Cuadernos de Turismo, $\mathrm{n}^{\circ} 29$, pp. 183-208.

PHILLIP, S., HUNTER, C. y BLACKSTOCK, K. (2010): “A typology for defining agritourism", Tourism Management, vol. 31 (6), pp. 754-758.

PULIDO FERNÁNDEZ, J.I. (Coord.) (2008): El turismo rural. Madrid, Síntesis.

ROBERTS, L. y HALL, D. (2001): Rural tourism and recreation: principles to practice. Oxon y Nueva York, CABI Publishing.

SAYADI, S. y CALATRAVA, J. (2001): “Agroturismo y desarrollo rural: situación actual, potencial y estrategias en zonas de montaña del sureste español”, Cuadernos de Turismo, $\mathrm{n}^{\circ}$ 7, pp. 131-157.

SHARPLEY, R. y VASS, A. (2006): "Tourism, farming and diversification. An attitudinal study", Tourism Management, vol. 27 (5), pp. 1.040-1.052.

SHAW, G. y WILLIAMS, A. (1994): Critical Issues in Tourism. Londres, Blackwell.

TEW, C. y BARBIERI, C. (2012): “The perceived benefits of agritourism: The provider's perspective", Tourism Management, vol. 33 (1), pp. 215-224.

URRY, J. (1990): The Tourist Gaze: Leisure and Travel in Contemporary Societies. Londres, Sage Publications. 